\title{
Pulmonary Complications following Percutaneous Nephrolithotomy: A Prospective Study
}

\author{
Gili Palnizky $^{\mathrm{a}} \quad$ Sarel Halachmi ${ }^{\mathrm{b}} \quad$ Michal Barak $^{\mathrm{c}}$

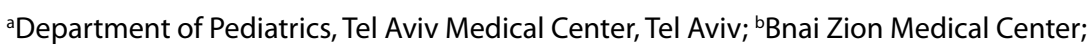 \\ 'Department of Anesthesia, Rambam Health Care Campus, Haifa, Israel
}

\section{Key Words}

Percutaneous nephrolithotomy • Anesthesia •

Post-operative pulmonary complications

\begin{abstract}
Introduction: Pulmonary complications may occur in the post-operative period and are a significant cause of morbidity and mortality in patients undergoing anesthesia and surgery. Complication rates vary according to different procedures and different types of anesthesia and may be affected by the patient condition. The purpose of this study was to examine pulmonary complications following percutaneous nephrolithotomy (PCNL) and to search for associations between the pre- and intra- operative factors and the risk of post-operative pulmonary complications (PPC). Patients and Methods: This was a prospective observational study of 100 consecutive adult patients who underwent PCNL surgery. We collected data of the patient, surgery and anesthesia and analyzed it to find correlations with PPC. Results: Eight (8\%) patients had PPC following PCNL, 7 patients had pneumothorax and 1 had atelectasis and pleural effusion. The latter patient died at post-operative day 24 due to respiratory failure. It was found that patients who had PCNL on the right kidney were at lower risk for PPC. In addition it was found that younger patients had a higher incidence of PPC. Conclusions: Based on this study the most common type of post-operative complication following PCNL is pulmonary, with pneumothorax being the main complication. PPC may result in patient mortality. The side of the operation and the patient's age might affect the risk of PPC.
\end{abstract}

Copyright $\odot 2013$ S. Karger AG, Basel

\section{KARGER}

Fax +4161306 1234

E-Mail karger@karger.ch

www.karger.com
(C) 2013 S. Karger AG, Basel

$1015-9770 / 13 / 0073-0113 \$ 38.00 / 0$

Accessible online at:

www.karger.com/cur

\section{Introduction}

Post-operative pulmonary complications (PPC) are not unusual following anesthesia and surgery, and their incidence may be higher than $10 \%$ [1-3]. These complications include atelectasis, pneumothorax, hemo- or hydro-thorax, pleural effusion, pulmonary edema, pneumonia, and acute respiratory distress syndrome. Important risk factors are advanced age, surgery near the diaphragm and poor health $[2,4,5]$. PPC are a significant cause of post-operative mortality and strategies to reduce them are continually being studied [6-8]. Patients undergoing percutaneous nephrolithotomy (PCNL) are at increased risk for PPC due to several factors. The operation is near the diaphragm and the patient is under general anesthesia. During the procedure the renal upper-pole approach may accidentally puncture the pleural cavity and the lung. During the procedure the urologist uses large volumes of irrigation fluids which may cause pulmonary congestion and edema if a minute fraction is absorbed into the blood stream. We report the results of a study of the occurrence of PPC following PCNL.

\section{Patients and Methods}

This was a prospective study of 100 consecutive adult patients who underwent elective PCNL under combined general-epidural anesthesia in our hospital. The study was approved by our local Ethics Committee.

Protocol

The pre-, intra- and post-operative management was similar for all the patients in the study. On admission to the hospital, the

All authors equally contributed to the manuscript.

Michal Barak

Department of Anesthesiology

Rambam Health Care Campus

IL-31096 Haifa (Israel)

E-Mail m_barak@rambam.health.gov.il 
Table 1. Data of the surgery

\begin{tabular}{ll}
\hline & Patients, $\mathrm{n}$ \\
\hline Surgery on & \\
$\quad$ Right side & 40 \\
$\quad$ Left side & 51 \\
$\quad$ Bilateral & 9 \\
Surgical approach & 79 \\
$\quad$ Upper-pole & 21 \\
$\quad$ Not upper-pole & 10 \\
Patients who had blood transfusion & \\
during surgery & $2.9 \pm 0.9(1.5-6.0)$ \\
Duration of surgery, hours &
\end{tabular}

patient was examined by an urologist and an anesthesiologist, who decided on the patient's American Society of Anesthesiologist Class (ASA) [9] and recorded the demographic data on the patient's file. One hour before the surgery the patient was pre-medicated with oral metoclopramide $10 \mathrm{mg}$ and diazepam $10 \mathrm{mg}$. On arrival at the operating room, the patient was monitored with non-invasive blood pressure, electrocardiogram and pulse-oximeter, and intravenous access and arterial line were established. The epidural catheter was inserted in the midline approach, at the level of L1-2. General anesthesia was induced with intravenous propofol $(2-3 \mathrm{mg} / \mathrm{kg}$ ) and fentanyl $(0.001-0.002 \mathrm{mg} / \mathrm{kg}$ ), followed by vecuronium $(0.08 \mathrm{mg} / \mathrm{kg})$. After endotracheal intubation and tube fixation were accomplished in the supine position, the patient was advanced to the distal end of the operating table and moved to the lithotomy position for cystoscopy and insertion of the ureter-catheter under radiographic guidance. Then the patient was turned to the prone position for the percutaneous nephrolithotomy. Under fluoroscopy, an 18 Fr needle was used to access the collecting system and a guide wire was inserted to the collection system. Thereafter, the tract was dilated to $25 \mathrm{Fr}$, an access sheath was inserted, and a rigid nephroscope and ultrasonic lithoclast (Olympus Corp., Japan) were used for stone destruction and removal. Following complete destruction of the stone, a 22 Fr nephrostomy tube was inserted (Cook Medical, Ireland). After completion of the procedure, the patient was turned to the supine position and extubated.

Following extubation the patient was transferred to the post-anesthesia care unit (PACU), where he/she stayed for 2 hours or more, and was treated with analgesics. The patient's oxygen saturation was recorded and a chest X-ray was performed. In case of pneumothorax, a chest drain was inserted. The patient was transferred to the ward with oxygen supplement through nasal canula or face mask, depending on the oxygen saturation at the time of discharge from PACU.

Data was collected for each patient concerning patient demographics, pre- and intra-operative parameters, and post-operative consequences. Statistical analysis was done using SigmaStat 3.5 (Systat Software, Inc. Ca, USA). Parametric data were summarized as mean and standard deviation $( \pm S D)$, and non-parametric data were summarized as median and range.

\section{Results}

One hundred consecutive patients were included in the study, 46 male and 54 female patients. The mean age was $54 \pm 16$ years. Mean weight was $78.8 \pm 16.2 \mathrm{~kg}$. ASA class distribution was: ASA I $=5$ patients; ASA II $=61 ;$ ASA III $=30 ;$ ASA IV $=4$ patients .

Seven patients had pre-operative chronic lung disease, 20 patients were smokers, 13 patients had a pre-operative blood creatinine level above normal and 23 patients had nephrostomy. Data about the operation is shown in table 1.

\section{Post-Operative Pulmonary Complications}

Eight $(8 \%)$ patients had pulmonary complications, 7 of them had pneumothorax which was managed with a chest drain. One patient had atalectasis and pleural effusion and died on the 24th post-operative day due to respiratory failure. Pneumothorax was suspected during surgery in 2 patients and proved to be wrong by routine chest X-rays in PACU.

The mean duration that a patient stayed in PACU was $2.8 \pm 1.0$ hours. Eleven patients were transferred to the ward without oxygen supplements, 70 patients with oxygen through nasal canulae, 18 with a face mask and 1 patient with a reservoir mask. Mean duration of hospitalization was $8.9 \pm 4.7$ days (range 3-34 days). Five patients had post-operative complications others than pulmonary: 2 had chest pain, 2 had sepsis and 1 had acute kidney bleeding.

Three patients died within 1 month of surgery, 1 with pulmonary complication, 1 had cardiac arrest on the 5th post-operative day, and 1 died on the 18th post-operative day due to klebsiela sepsis. Overall surgically related mortality was $3 \%$ while the mortality rate in patients with PPC was $12.5 \%$. Table 2 summarizes the occurrence of PPC and other factors.

Other factors that were assessed, such as blood sodium levels, baseline hematocrete, and arterial blood gas results, and were found to have no correlation to the occurrence of PPC in PCNL patients.

\section{Discussion}

In this study we found that the main post-operative complication following PCNL was pulmonary, affecting $8 \%$ of the patients, while $5 \%$ of the patients had post-operative complications that were not pulmonary. The most common PPC was pneumothorax, which was managed 
Table 2. Association between pre- and intra-operative factors and PPC

\begin{tabular}{|c|c|c|c|}
\hline & $\begin{array}{l}\text { Patients with } \\
\text { PPC }(n=8)\end{array}$ & $\begin{array}{l}\text { Patients without } \\
\text { PPC }(n=92)\end{array}$ & $\mathrm{p}$ \\
\hline Male/female & $3 / 5$ & $43 / 49$ & 0.82 \\
\hline Weight, $\mathrm{kg}$ & $71.7 \pm 12.4$ & $79.5 \pm 16.4$ & 0.19 \\
\hline ASA class: I / II / III / IV & $0 / 7 / 1 / 0$ & $5 / 54 / 29 / 4$ & 0.77 \\
\hline Patients with chronic lung disease & $0(0 \%)$ & $7(7.6 \%)$ & 0.93 \\
\hline Patients with nephrostomy & $1(12.5 \%)$ & $22(23.9 \%)$ & 0.77 \\
\hline \multicolumn{4}{|l|}{ PCNL } \\
\hline Right side & 0 & $40(43.5 \%)$ & 0.04 \\
\hline Left side & $7(87.5 \%)$ & $44(47.8 \%)$ & 0.07 \\
\hline Bilateral & $1(12.5 \%)$ & $8(8.7 \%)$ & 0.7 \\
\hline
\end{tabular}

with a chest drain in all the patients. One patient had atalectasis and pleural effusion with a fatal outcome. It was found that patients who had PCNL on the right side were at significantly lower risk for PPC. This may be the result of the difference in right and left kidney anatomy, specifically the kidney's level/height. Since the right kidney is 'lower' than the left, getting to its upper pole is easier than with the left kidney.

It was also found that younger patients had higher risk for PPC, with borderline significance of 0.05 . This is contrary to published studies that found that elderly patients suffer higher rates of PPC $[2,7,10]$. A possible explanation ffor this discrepancy is that surgeons tend to be more aggressive when the patient is younger, thus the procedure is more hazardous. To determine the truth of this, a prospective randomized study would have to be conducted, where each and every patient would be subjected to the technical characteristics that were previously selected, such as the approach: upper-pole or not.

Approaching the kidney from the upper pole has advantages, although it may be more difficult to perform and supposedly more injurious. Most of the patients in our study (79\%) had the upper-pole approach, although no significant difference in PPC occurrence was found between patients who had their upper pole approached and the others. Nevertheless, since the main complication was pneumothorax, it is reasonable to suspect that approaching the upper pole played a role in its occur- rence. In their retrospective study Netto et al. [11] found that the upper-pole approach carried a slight increase in the incidence of acceptable complications. Shilo et al. [12] published a similar study which found that upper and multiple access approaches were associated with a higher overall incidence of pleural effusion compared with the lower-pole access. The CROES Percutaneous Nephrolithotomy Global Study that examined the difference between upper- and lower-pole accesses found that the upper-pole access was associated with a higher incidence of hydrothorax [13].

Patient selection may also play a role in the complication rate [14]. In their review of complications in PCNL, Michel et al. [15] emphasized the importance of correct selection of patients in order to improve outcome, since co-morbidity increases the risk of complications. However, this approach is not unanimous [16]. In our study we found that previous chronic lung disease or history of smoking had no significant effect on the PPC rate. Also, patient's ASA class, as an indicator of patient's general health, was not significantly different in patients with or without PPC. Our conclusions are that PCNL should not be avoided in patients with co-morbidity. Individually managed intra- and post-operative care should be customized to the patient and his/her condition and diseases, thus keeping the complication rate reasonable in all patients. 


\section{References}

-1 Lawrence VA, Dhanda R, Hilsenbeck SG, Page CP: Risk of pulmonary complications after elective abdominal surgery. Chest 1996; 110:744-750.

2 Rock P, Rich PB: Postoperative pulmonary complications. Curr Opin Anaesthesiol 2003; 16:123-132.

3 Canet J, Mazo V: Postoperative pulmonary complications. Minerva Anestesiol 2010;76: 138-143.

-4 Smetana GW, Lawrence VA, Cornell JE; American College of Physicians: Preoperative pulmonary risk stratification for noncardiothoracic surgery: systematic review for the American College of Physicians. Ann Intern Med 2006;144:581-595.

$\checkmark 5$ Canet J, Gallart L: Predicting postoperative pulmonary complications in the general population. Curr Opin Anaesthesiol 2013;26: 107-115.

6 Lawrence VA, Cornell JE, Smetana GW; American College of Physicians: Strategies to reduce postoperative pulmonary complications after noncardiothoracic surgery: systematic review for the American College of Physicians. Ann Intern Med 2006;144:596608.
-7 Smetana GW: Postoperative pulmonary complications: an update on risk assessment and reduction. Cleve Clin J Med 2009; 76(Suppl 4):S60-65.

8 Kilpatrick B, Slinger P: Lung protective strategies in anaesthesia. Br J Anaesth 2010;105 (Suppl 1):i108-116.

9 American Society of Anesthesiologists: http://www.asahq.org/clinical/physicalstatus. htm

10 Okeke Z, Smith AD, Labate G, D'Addessi A, Venkatesh R, Assimos D, Strijbos WE, de la Rosette JJ; CROES PCNL Study Group: Prospective comparison of outcomes of percutaneous nephrolithotomy in elderly patients versus younger patients. J Endourol 2012;26: 996-1001.

11 Netto NR Jr, Ikonomidis J, Ikari O, Claro JA: Comparative study of percutaneous access for staghorn calculi. Urology 2005;65:659662 .

12 Shilo Y, Kleinmann J, Zisman A, Peer A, Lindner A, Siegel YI: Comparative morbidity for different accesses in percutaneous nephrolithotripsy. Harefuah 2006;145:107-110.
13 Tefekli A, Esen T, Olbert PJ, Tolley D, Nadler RB, Sun YH, Duvdevani M, de la Rosette JJ; CROES PCNL Study Group: Isolated upper pole access in percutaneous nephrolithotomy: a large-scale analysis from the CROES percutaneous nephrolithotomy global study. J Urol 2013;189:568-573.

14 Tyson MD, Humphreys MR: Postoperative complications after percutaneous nephrolithotomy: a contemporary analysis by insurance status in the United States. J Endourol 2013.

15 Michel MS, Trojan L, Rassweiler JJ: Complications in percutaneous nephrolithotomy. Eur Urol 2007;51:899-906.

16 Nouralizadeh A, Lashay A, Ziaee SA, Ahanian A, Sharifi SH, Nikkar MM, Ojand A, Soltani MH: Percutaneous nephrolithotomy in high-risk patients: a single-center experience with more than 350 cases. Urol Int 2013;90:394-398 